\title{
O TROTE NO CURSO DE PEDAGOGIA E A PRAZEROSA INTEGRAÇÃO SADOMASOQUISTA
}

\author{
ANTÔNIO ÁlVARo SOAREs Zuin
}

\begin{abstract}
Sabia, sim, que jovem sem instrução é violento, não tem cabeça. Mas pensava que estudante de medicina, aluno da USP conhece o certo e o errado. Se estudou mais, deve ser mais humano, mais educado, mais familiar. É uma lógica matemática. Não sabia que na faculdade meu filho ia encontrar mesmo perigo da rua.

(Feng Ming Hsueh, pai do calouro Edison Tsung-Chi Hsueh que foi encontrado morto no clube da Faculdade de Medicina da USP, em fevereiro de 1999)
\end{abstract}

RESUMO: O texto propõe-se a investigar a existência de um processo psicossocial de integração sadomasoquista (os chamados "trotes") entre os calouros e veteranos do curso de Pedagogia da Universidade Federal de São Carlos. Através da análise dos dados coletados, pode-se concluir que o trote universitário é um rito de passagem, cuja violência física e, principalmente, psíquica, é justificada, pelos alunos, como uma tradição que deve ser mantida na vida universitária.

Palavras-chave: Trote universitário. Theodor W. Adorno. Indústria Cultural.

\section{Hazing in the Faculty of Education AND THE PLEASENT SADOMASOCHIST INTEGRATION}

ABSTRACT: This paper intends to investigate the existence of a psychosocial process of sadomasochist integration (the so-called "hazing") between freshmen and veterans in the Faculty of Education at the Federal University of São Carlos. The analysis of the collected

Professor-Adjunto do Departamento de Educação da Universidade Federal de São Carlos (UFSCAR) e um dos coordenadores do grupo de pesquisa Teoria Crítica e Educação (UFSCAR/ UNIMEP/UNESP - Araraquara, SP). E-mail: dazu@power.ufscar.br 
data indicates that university hazing is a passage rite whose physical and mainly psychic violence is justified by students as a tradition that must be maintained in the university life.

Key words: University hazing. Theodor W. Adorno. Cultural Industry.

\section{Introdução}

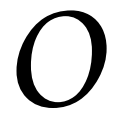

lamento de Feng Ming Hsueh, diante do filho que foi morto após a aplicação de um trote numa das mais conceituadas faculdades de medicina do país, torna-se, paradoxalmente, revelador não só de uma tragédia pessoal como também do horror do espírito de um tempo, de uma cultura. Causa enorme consternação o desalento do pai de que, na universidade, os agentes educacionais teriam as condições de discernir automaticamente entre o certo e o errado, ou seja, de que a atitude ética seria uma conseqüência indefectível das benesses engendradas pelo progresso da instrução.

Mas a origem de tal consternação não pode ser localizada apenas na sociedade contemporânea, pois ela expressa em si tanto o sonho como a frustração de que a instrumentalização da razão conduziria, de forma inequívoca, o homem à sua condição de indivíduo emancipado. A alusão à lógica matemática que considera a ética um produto inevitável do processo educativo lembra uma outra equação destacada por Adorno e Horkheimer. Com efeito, foram os frankfurtianos aqueles que observaram, já no Novum organum, de Francis Bacon, que a matemática e a justiça se encontravam administradas pelo princípio da equivalência: "As mesmas equações dominam a justiça burguesa e a troca mercantil. 'Não é a regra: se adicionares o desigual ao igual obterás algo de desigual' um princípio tanto da justiça como da matemática?” (Adorno \& Horkheimer, 1986b).

Se a justiça e a matemática são regidas pelo princípio de equivalência, pode-se argumentar que uma equação semelhante estaria presente na veleidade de que, nesta sociedade pretensamente mais justa, o processo educativo/formativo, sendo bem-sucedido, produziria indivíduos mais instruídos que seriam, consequentemente, mais humanos, mais educados. Contudo, há vários fatos que desmentem esse desejo e que desvelam a essência de uma cultura cujo progresso das forças produtivas exige a concomitante regressão das capacidades físicas e espirituais de seus produtores.

Recentemente, a sociedade brasileira assistiu, estupefata, ao assassinato do índio Galdino, da tribo pataxó, cometido por adolescentes muito 
bem nutridos e instruídos. Na noite de 20 de abril de 1997, cinco adolescentes atearam fogo no índio Galdino dos Santos, da tribo pataxó, que estava dormindo em uma parada de ônibus de uma das vias de Brasília, fugindo em seguida. Tal acontecimento ilustra muito bem uma fissura nos alicerces daquela promessa do capitalismo incipiente de que o consumo universalizado de bens culturais (os quais não por acaso se transformam hegemonicamente em mercadorias) proporcionaria a efetivação da veracidade de seus conteúdos ideológicos de liberdade, igualdade e fraternidade. É interessante observar que tal ato foi justificado como uma brincadeira infeliz, como se o fato de alguém, deliberadamente, jogar álcool num ser humano e riscar um fósforo em seguida não pudesse ser classificado como um crime com requintes sádicos.

Mas há um certo fio condutor entre o indivíduo dessensibilizado, que comete tal barbárie e que trata o outro como coisa para não ter que encarar o seu próprio processo de coisificação, e o riso de identificação que é prazerosamente fruído quando alguém se diverte, sadicamente, com a propaganda do posto de gasolina cujo bordão refere-se ao suposto amor que o brasileiro tem pelo seu carro: a forma delicada como o homem acaricia e cobre o veículo contrasta com a maneira pela qual sua companheira é tratada, pois quando ele se deita na cama puxa imediatamente o cobertor para si, descobrindo a "companheira". A repugnância pelo outro se insere num caldo de cultura que estimula o deslocamento da libido para as mercadorias e suas representaçōes numa intensidade que não pode ser mensurada, pois tal tentativa apenas poderia recrudescer o desdém ao qual o indivíduo é submetido quando se transforma em algo que pode ser intercambiável, como se fosse uma mercadoria qualquer.

Se se torna difícil mensurar quantitativamente a barbárie numa sociedade que a banaliza no cálculo, na operação do procedimento científico que anseia ser totalmente neutro em relação aos seus desdobramentos sociais, não deixa de ser menos relevante a necessidade de investigação de tais regressões com o propósito de auxiliar a auto-reflexão dos educadores e dos educandos, os quais, sem que possam muitas vezes perceber, reproduzem a violência nos atos mais corriqueiros.

Dentre estes, talvez, atualmente, o trote universitário possa ser identificado como um rito de passagem cujas violências física e psíquica são justificadas como uma tradição que deve ser perpetuada durante o processo de integração entre os calouros e os veteranos das universidades. É como se os agentes educacionais fossem simpáticos à manutenção desta tradição que se transforma numa segunda natureza, de tal modo que 
parece não haver outra alternativa de integração a não ser aquela pautada na humilhação. Desse modo, este artigo possui como principal objetivo investigar a reprodução de um possível processo psicossocial sadomasoquista presente entre os calouros e veteranos do curso de Pedagogia da Universidade Federal de São Carlos (UfSCAR) durante os ritos de passagem (os chamados "trotes") destes calouros.

Procura-se argumentar que há uma certa aceitação por parte dos agentes educacionais, e da própria universidade, quanto à manutenção de um trote que, se por um lado, não resulta na morte ou mutilação física de algum calouro, por outro, não deixa de se fundamentar em práticas de subserviência e humilhação que passam a ser consideradas normais e que podem engendrar seqüelas psicológicas não tão evidentes à primeira vista. Neste sentido, os próprios alunos parecem justificar a perpetuação de um trote mais "ameno", quando este é comparado com aqueles nos quais os calouros são agredidos explicitamente. A seguir, uma investigação mais detalhada dos trotes realizados no curso de Pedagogia da UfSCAR.

\section{O trote no curso de Pedagogia da UfSCAR}

Através da análise dos dados coletados por meio da aplicação de um questionário, de entrevistas com as calouras e veteranas e de observaçôes de campo, pode-se afirmar que as novatas do curso de Pedagogia, de forma geral, aprovaram a maneira como foram recebidas por suas colegas mais experientes. De fato, houve alguns momentos no quais as calouras afirmaram se sentir próximas às veteranas, tal como na ocasião em que as novatas se apresentaram para as novas colegas de curso e falaram um pouco sobre suas cidades de origem e as respectivas primeiras impressões que tiveram da UfSCAR.

Porém, isso não significa que a integração entre as novatas e suas veteranas tenha se pautado num ambiente destituído de humilhação e sofrimento. Pelo contrário, a maior parte das calouras parece justificar os trotes recebidos como algo que faz parte de uma tradição que deve ser mantida, pois ajuda a aproximar os alunos, mesmo que haja algum tipo de constrangimento. $\mathrm{O}$ fato das veteranas terem fornecido uma opção de escolha para que a próprio caloura decidisse se gostaria ou não de participar dos trotes aplicados parece servir como racionalização (tanto por parte das calouras como das veteranas) para a conclusão majoritária de que não houve violência alguma nas atividades de recepção, ou seja, nos chamados trotes. 
Das quarenta novatas que responderam as perguntas do questionário, dezesseis (40\%) afirmaram que temiam receber algum tipo de violência física e/ou psicológica por parte dos veteranos. Duas calouras que responderam afirmativamente a questão mencionaram a morte do calouro Edison Tsung-Chi Hsueh como causa principal de suas preocupações. Já uma outra disse o seguinte: "Sim, mas não necessariamente violência. Seria no sentido de brincadeiras indesejáveis como, por exemplo, corte de cabelo". Para a novata, cortar o cabelo de alguém é uma atividade que não é necessariamente violenta, mas sim uma brincadeira indesejável.

$\mathrm{Na}$ questão sobre se o modo como as veteranas as receberam correspondeu às suas expectativas, uma destas novatas disse que a recepção havia sido muito boa. Esta mesma caloura afirmou que, se esperava um sofrimento maior, teve uma boa surpresa, pois se divertiu bastante e isso foi importante para que pudesse conhecer melhor suas colegas de classe. Já uma outra caloura, ao responder que não tinha receio de sofrer algum tipo de violência física e/ou psicológica, também lembrou a morte de Edison da seguinte forma: "Não, pois esses tipos de violência parecem ter diminuído após a morte do calouro de medicina em São Paulo. Parece que precisou ocorrer para haver consciência”.

Nota-se a semelhança dos raciocínios das calouras nos conteúdos das respostas que são contrastantes apenas na aparência. Tanto a novata que temia sofrer algum tipo de violência física e/ou psicológica, e que se sentiu aliviada, pois pensou que iria sofrer mais durante os trotes, como a caloura que não tinha receio de ser recebida de maneira agressiva associaram o trote violento com a morte do estudante. As atividades tais como pinturas das faces com a palavra "Bichete 2000" ou "Bichete burra", o "pedágio" e a aula-trote não foram consideradas por elas como violentas, sendo que a maioria delas, ou seja, trinta novatas ( $75 \%$ da turma) concordou com este raciocínio. ${ }^{1}$ A caloura que respondeu temer sofrer alguma agressão foi a mesma que disse que estas atividades não podem ser identificadas como violentas pois, “... é até bom ficar com a cara pintada e mostrar pra todo mundo que EU ENTREI!!!!”.

As letras maiúsculas do seu depoimento sinalizam tanto a alegria de ter sido aprovada no vestibular como a possibilidade de ser reconhecida como uma nova integrante na universidade. Talvez esta sua afirmação de que é até bom ter a face pintada (sobretudo a ênfase dada à palavra até) possa ser lida como um alento ao seu desejo de poder se desforrar da tensão acumulada durante o período de preparação para o vestibular e poder então mostrar para todos que foi aprovada. Mas a sua aprovação 
não se restringe ao fato de que demonstrou ter certo domínio dos conteúdos referentes às disciplinas de física, matemática, português ou geografia. A novata parece ter assimilado muito bem uma lição essencial para a aprovação e permanência na vida universitária, pois é como se ela dissesse o seguinte: "o preço que tenho que pagar pelo desdém ao qual sou submetida, nesse momento em que sou pintada pelas veteranas e chamada de 'bichete burra', não é nada comparado com o prazer que sinto em poder humilhar, através de minha humilhação, a sociedade que me agrediu e que agora encara de frente a agressão que está estampada em mim, na mais nova 'bichete".

Identifica-se o realce dado pela novata à sua entrada na vida universitária tanto nas respostas de suas trinta colegas de que as atividades de recepção, tais como as pinturas nas faces e nos cabelos, a aula-trote e o "pedágio" não podem ser caracterizadas como elementos de um trote violento, como também na declaração da mãe de um calouro que, durante a chamada semana da matrícula, disse que raspar o cabelo ou pintar o rosto de seu filho era pouca coisa, até mesmo algo sem graça, pois se fosse ela a veterana teria feito muito mais. A justificativa para o exercício do sadismo da aluna coaduna-se ao depoimento da mãe que afirmou que seu filho não poderia voltar para casa sem portar sinais (pintura das faces e cabelo raspado) que o identificassem como alguém que havia sido aprovado na USP (Frias, Folha de S. Paulo, 2000).

O que realmente interessa é a produção de uma imagem que o destaque de alguma forma, que o faça impressionar. No artigo "Sociedade da sensação: A estetização da luta pela existência”, Chistoph Türcke, baseado no pensamento de Theodor W. Adorno, faz uma relevante análise das transformaçōes históricas do significado do termo sensação: se, para Locke, sensação significou percepção simples e imediata de um objeto, já na sociedade contemporânea o termo sensação se transformou na "excitação maciça, na embriaguez destrutiva, no choque como bem de consumo" (Adorno, 1992).

$\mathrm{Na}$ sociedade cuja industrialização da cultura é hegemônica, o sentir adjudica-se ao impressionar, àquilo que se destaca, que se sobressai, a ponto da ética se transformar numa categoria estética. Türcke menciona o caso dos polêmicos cartazes publicitários da marca de roupas Benetton para expor seu raciocínio:

O cartaz da Benetton, que mostra uma roupa suja de sangue de sérvios fuzilados por soldados bósnios, teve apenas um objetivo: impressionar. Sua violação do tabu representou, antes de mais nada, uma rigorosa obediência às 
leis do mercado (...) quando aquilo que impressiona é considerado bom, pois torna-se necessário para a sobrevivência, então o que é impressionável não pode ser ruim. Dessa forma, o bom e o mal se transformam em categorias estéticas; e o estético se transforma no ontológico, na possibilidade de ser ou não ser. (Türcke, 1995)

Se, na sociedade da indústria cultural hegemônica, o ético se transforma no estético que, por sua vez, condiciona a própria existência do indivíduo, então compreende-se os anseios das mães de que seus filhos portassem sinais que indicassem o quão foram bem sucedidos nos vestibulares da Universidade de São Paulo e da Universidade Federal de São Carlos. O preço da exibição de tais sinais é a humilhação à qual seus filhos são submetidos? Não importa, paga-se com prazer, pois o que interessa é poder impressionar. E se estes vestígios de violência já se encontram tão vulgarizados, a ponto de não mais cumprirem sua função de proporcionar o devido destaque daquele que os expõe, faz-se necessário que sejam intensificados para que possam novamente propiciar o desejado reconhecimento por parte das outras pessoas. Não foi por acaso, portanto, que aquela mãe de um dos calouros da UFSCAR asseverou que raspar cabelos e pintar as faces de seu filho era pouca coisa, pois se ela fosse veterana teria feito muito mais do que isso.

Ora, uma sociedade violenta reconhece como seus integrantes aqueles que portam seus vestígios. E esta aceitação é ainda maior se os seus integrantes não reconhecem em si mesmos estes sinais, ou seja, se a banalização de atos violentos torna-se uma segunda natureza que se espraia em todas as relações sociais, na medida em que as pessoas vão se tornando cada vez mais dessensibilizadas, tanto em relação ao sofrimento que precisam suportar como na imposição desta dor ao outro. No caso da vida universitária, é justamente um modelo de educação que referenda este processo sadomasoquista de integração: a chamada educação para a disciplina através da dureza. O conceito de educação para a disciplina através da dureza foi exposto na palestra de Adorno na rádio de Hessen, em 18 de abril de 1965, que foi posteriormente publicada com o título de Educação após Auschwitz. Poucos anos após o final da Segunda Guerra Mundial, houve, na Alemanha, um clima geral simpático à defesa de um procedimento "educativo" cuja característica central era a do elogio da chamada firmeza de caráter. O louvor à virilidade seria a condição fundamental para o ressurgimento de um espírito objetivo que alavancaria a recuperação não só econômica como também cultural do povo germânico.

Neste tipo de modelo "educativo", as crianças deveriam ser ensinadas a evitar o contato e, sobretudo, a reflexão sobre os seus sentimentos de 
insegurança e/ou quaisquer comportamentos que denotassem algum indício de fragilidade ou sensibilidade. A sua palavra de ordem aferrava-se à necessidade de ser forte e de se esquivar de qualquer tipo de hesitação que poderia ser o primeiro passo para o esmorecimento, para a consternação e, quem sabe, para a indesejada auto-reflexão crítica. Adorno percebeu o recrudescimento da propensão dos alemães em apoiar tal modelo "educativo" e, imediatamente, insurgiu-se contra o próprio, tal como se pode notar de acordo com estas palavras:

A idéia de que a virilidade consiste num grau máximo da capacidade de suportar dor de há muito se converteu em fachada do masoquismo que como mostrou a psicologia - se identifica com muita facilidade ao sadismo. $\mathrm{O}$ elogiado objetivo de "ser duro" de uma tal educação significa indiferença contra a dor em geral. No que, inclusive, nem se diferencia tanto a dor do outro e a dor de si próprio. Quem é severo consigo mesmo adquire o direito de ser severo também com os outros, vingando-se da dor cujas manifestaçôes precisou ocultar e reprimir. (Adorno, 1995)

É verdade que as veteranas do curso de Pedagogia ofereceram a oportunidade da caloura escolher se desejaria ou não receber os trotes anteriormente mencionados. De fato, não houve uma ordem explícita, uma imposição direta para que a novata se submetesse ao trote contra a sua vontade e, portanto, poderia haver um equívoco em se estabelecer uma relação de correspondência entre o trote e a chamada educação para a disciplina através da dureza.

Mas dois fatos parecem encaminhar o raciocínio para uma reflexão oposta: o primeiro é o de que a maioria das calouras desejou participar destas atividades de recepção, pois sentiu a importância destas brincadeiras "saudáveis" para marcar o sucesso de ter sido aprovada no vestibular, mesmo que às custas de uma humilhação coletiva que, de certa forma, amainou o constrangimento individual; o segundo fato refere-se ao depoimento da novata que, ao ser questionada se a realização dos trotes facilitou a integração entre caloura e veterana, asseverou: "Sim, foi fundamental. Quem não participou ficou um pouco deslocado depois". A leitura destes dizeres permite relembrar as palavras de Adorno e Horkheimer, fundamentadas no pensamento de Tocqueville, de que, na sociedade capitalista contemporânea, as pessoas são "livres" para refletir e questionar a adesão cega a esta forma de produção da existência que impinge a internalização da lógica do fetiche da mercadoria em todas as relações sociais, mas se de fato assim procederem serão estranhadas, ou melhor, marginalizadas (Adorno \& Horkheimer, 1986a). 
Se a maior parte das novatas respondeu que os trotes recebidos foram determinantes para que confirmassem suas respectivas identidades de calouras integradas na vida universitária, então se pode imaginar o significado da indiferença ou mesmo raiva da veterana em relação àquela que ousou romper com as regras da tradição sadomasoquista de integração.

No cômputo geral, a caloura parece refletir que é muito melhor permitir a diluição da sua humilhação no termo genérico "bichete" (da mesma maneira como todas as suas outras colegas são chamadas) do que se rebelar contra as cláusulas contratuais dos trotes, pois pode ser identificada como a inconveniente que ainda não se deu conta de que não é mais uma aluna do ensino médio, mas sim uma caloura universitária.

Se pôde ser observado um processo psicossocial de integração sadomasoquista nas ocasiōes da pintura das faces e do "pedágio" das novatas, talvez nada seja mais representativo da sua existência do que a aula-trote que foi aplicada. Todas as atividades humilhantes observadas durante a sua realização não foram consideradas agressivas pela maioria das novatas (75\%). A rudeza do aluno que representou o papel de professor, e que expulsou da sala-de-aula, aos berros, duas das novatas, não foi considerada uma atitude violenta. E foi este mesmo "professor" aquele que ameaçou as calouras, pois caso estas não fossem pontuais e não estudassem iriam se "ferrar", ou seja, seriam reprovadas sem a mínima hesitação.

Os abraços entre as veteranas e as novatas que ocorreram no término da aula-trote, após os gritos das veteranas ("Bicharada burra, chupa! E vai pra puta que te pariu, i, ó!”), parecem ter dirimido a humilhação geral e, concomitantemente, sacramentado o acordo tácito entre os alunos de que, no próximo ano, será feita a vingança dos que agora foram ridicularizados.

Parece haver uma correspondência entre os dados obtidos por meio dos questionários aplicados e os elementos coletados através das entrevistas feitas com as calouras sobre suas opiniōes a respeito da aula-trote, do "pedágio" e das outras atividades anteriormente descritas. As novatas que foram entrevistadas, de forma geral, não consideraram a aula-trote como violenta. É verdade que uma das novatas confessou ter ficado apavorada quando foi expulsa da aula-trote pelo aluno "professor". Mas foi esta mesma caloura que disse ter adorado esta experiência e que quando for uma das veteranas será responsável pela aplicação da aula-trote nos próximos novatos. Para poder ser mais convincente, esta caloura disse que o "professor" não deverá ser tão carrasco no começo, mas sim dissimular seu autoritarismo que aparecerá aos poucos, pois se ele proceder 
deste modo, segundo suas próprias palavras, enganará melhor os "bichos". Este sentimento de revanche não pode ser reduzido a esta opinião específica, pois vinte e nove calouras $(72,5 \%$ da turma) responderam que desejam participar da aplicação dos mesmos trotes quando se tornarem veteranas.

Os efusivos abraços dados em suas calouras, após terem-nas chamado de "bicho burro" no final da aula-trote, são relevantes indícios de uma prazerosa identificação masoquista, pois finalmente elas puderam não só gozar a dor que tiveram que reprimir no ano passado, quando foram humilhadas na condição de "bichetes" que precisavam ser "domesticadas", como também exercer sadicamente os desejos de onipotência do ego por meio da concretização do narcisismo coletivo legitimado pelo grupo das veteranas, uma vez que a todas está assegurado o direito de projetarem seus desejos agressivos reprimidos na figura autoritária do "professor".

A caloura sente, no seu íntimo, que está sendo ridicularizada através de sua participação em algumas atividades vexatórias. Mas ela parece também conter sua revolta, a qual transpareceu em algumas respostas na análise do questionário, ao considerar que isto tudo faz parte do jogo, ou melhor, faz parte da tradição, uma tradição que se hipostasia até chegar a se tornar uma segunda natureza. Diante deste quadro geral, um comentário feito pela novata logo em seguida ao término da aula-trote, "Fizeram a gente de palhaços", soa como algo quase anacrônico.

Frente a este quadro, talvez fosse possível avultar a existência de um paradoxo: a aula-trote, que deveria ser o símbolo do engodo ao qual a caloura é submetida, na dissimulação de uma aula ministrada de maneira autoritária, parece converter-se na ocasião em que a veterana expressa o quão é sincera, ou seja, neste momento ela está sendo o mais transparente possível quando exterioriza a raiva e o ressentimento recalcados (numa verdadeira catarse regressiva), os quais não puderam ser explicitados nas relaçóes estabelecidas no cotidiano escolar com seus respectivos preceptores. Onde deveria haver o logro, faz-se presente a autenticidade de um processo "educativo" sadomasoquista, no qual as calouras participam de uma prévia, ainda que de uma forma mais "caricata", das relações cotidianas que serão desenvolvidas com alguns de seus mestres. De fato, uma da veteranas esclareceu quais seriam os fatores motivadores para a elaboração da aula-trote: "Parece que é mais para assustar as pessoas... É um pouco mau falar isso, mas essa é que é a verdade, é para as pessoas assustarem, se você for pensar bem no sentido é o susto, você quer passar medo, é como se falasse: 'Tá vendo como é fogo? Você entrou aqui e agora está ferrada!', eu acho que é isso. A intenção 
de todo mundo é essa. Quando você vê os rostos dos calouros quando tem a aula-trote só vê que está todo mundo morrendo de medo”.

Uma das principais conclusôes de Adorno no artigo "Educação após Auschwitz" foi a de que, diante das práticas "educativas" sadomasoquistas da chamada educação para a disciplina através da dureza, tornase fundamental a não repressão do medo. É preciso fazer com que este processo de integração sadomasoquista na vida universitária seja cada vez mais discutido e não aceito em virtude da justificativa de se tratar de uma tradição que não pode ser alterada. Ora, por que novas tradições não podem ser engendradas? Ao fazer a crítica da educação para a disciplina através da dureza, Adorno afirmou que:

(...) a educação precisa levar a sério o que já de há muito é do conhecimento da filosofia: que o medo não deve ser reprimido. Quando o medo não é reprimido, quando nos permitimos ter realmente tanto medo quanto esta realidade exige, então justamente por essa via desaparecerá provavelmente grande parte dos efeitos deletérios do medo inconsciente e reprimido. (Adorno, 1995)

Neste pensamento ressoa também a idéia freudiana de que os professores que exigem que seus alunos sejam aprioristicamente virtuosos fazem mau uso das exigências éticas, pois não refletem com eles sobre os motivos pelos quais as pessoas não são éticas, como se os desejos agressivos recalcados não encontrassem algum tipo de escoadouro nas mais variadas relações do cotidiano escolar (Freud, 1997). A possibilidade da criação de novas tradições, no que diz respeito à maneira como os calouros são recebidos pelos seus veteranos, não se limita apenas à conscientização da existência e da reprodução de um processo "educativo" sadomasoquista, pois vivemos numa sociedade cuja produção da própria existência impinge a contínua dessensibilização de seus partícipes.

Porém, não deixa de ser uma tarefa importante explicitar o fato de que os agentes educacionais favoráveis à manutenção dos trotes descritos contribuem ainda mais para aumentar o fosso existente entre a promessa da cultura fundamentada no progresso de uma vida mais humana e sua efetiva realização. Mas as vozes discordantes que indicam outras alternativas de integração e, portanto, de novas identidades, ainda podem ser escutadas, tal como na questão que uma das calouras fez quando opinou sobre a possibilidade de haver um outro tipo de recepção dos novatos: "A recepção precisa ser mais civilizada. Existem muitas possibilidades de recepção. Por que ela se chama trote?" Uma questão como esta relembra o imperativo kantiano da necessidade de ousar saber, mesmo que para isso tenhamos que nos defrontar com a permanência do lamento de Feng Ming Hsueh, cujo choro diante do 
filho morto teima em evidenciar nossa ilusão de que uma postura ética frente ao outro seria uma conseqüência inexorável do progresso dos procedimentos educativos empregados nas instituiçóes escolares. E se este pranto ainda pode provocar sensibilização e reflexão, isto significa que ainda não foi eliminada a possibilidade da construção de novas tradições concernentes às recepções dos calouros na vida universitária.

Recebido em setembro de 2001 e aprovado em maio de 2002.

\section{Nota}

1. No chamado "pedágio", as novatas dançaram, de forma sensual e, logo após, pediram dinheiro para os motoristas dos automóveis nas esquinas da cidade, sendo que o montante amealhado foi entregue para as veteranas. Já na aula-trote, um aluno veterano foi escolhido para representar, autoritariamente, o papel do professor diante das assustadas novatas.

Referências bibliográficas

ADORNO, T.W. "Edição extra". In: Adorno, T.W. Minima moralia. Tradução de Luiz Eduardo Bicca, São Paulo: 1992.

."Educação após Auschwitz”. Tradução de Wolfgang Leo Maar. In: Adorno, Theodor W., Educação e emancipação, Rio de Janeiro: Paz \& Terra, 1995.

ADORNO, T.W.; HORKHEIMER, M. "A indústria cultural: O esclarecimento como mistificação das massas". In: Adorno, T.W.; HorkHEIMER, M. Dialética do esclarecimento - Fragmentos filosóficos, tradução de Guido Antonio de Almeida, Rio de Janeiro: Zahar, 1986a.

. "O conceito de esclarecimento". In: Adorno, T.W.; HorkHEIMER, M. Dialética do esclarecimento - Fragmentos filosóficos, tradução de Guido Antonio de Almeida, Rio de Janeiro: Zahar, 1986b.

FREUD, S. O mal-estar na civilização. Tradução de José Otavio de Aguiar Abreu, Rio de Janeiro: Imago, 1997.

FRIAS FILHO, Otavio. Ele não podia voltar para casa sem mostrar que passou na USP. Folha de S. Paulo, São Paulo, 9 fev. 2000, Opinião, p. 1.

TÜRCKE, C. "Sensationsgesellschaft: Ästhetisierung des Daseinkampfs". In: SCHWEPPENHÄUSER, G.; WISCHKE, M., Impuls und negativität: Ethik und Ästhetik bei Adorno, Hamburg: Argument Verlag, 1995. 